\title{
TRANSITION OF BISMUTH TO LEAD IN THE PULSE ELECTROMAGNETIC FIELD
}

\section{Vladimir F. Balakirev}

Institute of Metallurgy of the Ural Branch of the Russian Academy of Sciences, http://www.imet-uran.ru Ekaterinburg 620016, Russian Federation

vfbal@mail.ru

Valeriy V. Krymsky, Nataliya V. Plotnikova

South Ural State University, http:/ /www.susu.ru

Chelaybinsk 45408, Russian Federation

krymskiivv@susu.ru, plotnikovanv@susu.ru

Absract. Impact of powerful nanosecond electromagnetic impulses (NEMI) on fusions containing lead and bismuth is considered. The main controlled property is chemical composition. Special pulse generators are used for influence. They produce pulses of the positive polarity with duration of 1 nanosecond on a half-height, with amplitude of $6-10 \mathrm{kV}$ and repetition frequency of $1 \mathrm{kHz}$. Processing of NEMI is carried out directly in a crucible into which the copper tube or a core is inserted. Outputs of the generator connect with a crucible and a tube. Time of processing is tens of minutes. The level of $\alpha$-radiation and $\beta$-radiation of solid metal is measured before and after processing. There are given the results of 4 experiences in which the reduction of amount of bismuth by $8-10 \%$ and the same in size increase of amount of lead is noted. For one of experiences the analysis of the chemical composition is carried out on three devices, various on type. The theory of electronic capture under the influence of NEMI and change of isotope structure without change of mass of a kernel are offered as theoretical base. Results which describe transformation of tens of grams of bismuth into the same amount of lead are absent in available literature.

Keywords: impulse, field, nanosecond, transition, bismuth, lead

UDC 544.032

Bibliography -12 references

Received 28.03.2017

\section{CONTENTS:}

1. INTRODUCTION (106)

2. EXPERIMENTAL RESEARCHES (107)

3. Analysis of results (109)

4. Theoretical substantiations (111)

5. Conclusion (111)

REFERENCES (111)

\section{INTRODUCTION}

Some results of influence of powerful nanosecond electromagnetic impulses (NEMI) on fusions of metals and solutions of salts are given [1-3]. The essence of the method is that fusion of metal is affected by influence of unipolar electromagnetic impulses lasting less than 1 ns with an amplitude more than $5 \mathrm{kV}$ without carrier frequency. Impulses are generated by special generators which have small dimensions and weight, consume the power from a network less than 100 W. In our researches we used generators with next parameters: amplitude of impulses is $7-10 \mathrm{kV}$, duration is $1 \mathrm{~ns}$, the frequency of repetition is $1 \mathrm{kHz}$.

The impulse from the generator exit is transferred on the radiator. We used radiators in the form of a piece of the coaxial line. The crucible performs function of the external conductor and has to be 
the current conductor, for example, graphite. The nonconducting crucible is inserted into carrying-out screen. The central conductor is made from copper or graphite and located in a protective tube. It separates a radiator from fusion and is made from quartz. It can not be used at low temperatures of fusion.

Many mechanical properties change at the hardened metal after processing of fusions of metals by NEMI. For example, durability and plasticity increase at the same time, impact strength at low temperatures increases [1-4]. Questions of change of the chemical composition of fusions and solutions under the influence of big pulse currents are considered in [5-7].

The purpose of work is experimental research of impact of powerful NEMI on change of the chemical composition of leadbismuth fusion.

\section{EXPERIMENTAL RESEARCHES}

Experience 1. Radiation of Roze alloy ( $\mathrm{Pb}$, $\mathrm{Bi}, \mathrm{Sn})$. Alloy is standard. The composition of elements according to the passport (masses\%) is the next: $\mathrm{Pb}-32.87 ; \mathrm{Bi}-49.11$; $\mathrm{Sn}-17.95 ; \mathrm{Sb}-0.04 ; \mathrm{Cu}-0.01$; As - 0.01; $\mathrm{Fe}-0.006$.

Experimental conditions: the mass of an alloy is $0.5 \mathrm{~kg}$, the crucible graphite $\varnothing 45$ with internal dimensions, depth is $90 \mathrm{~mm}$. Radiator is the copper rod Ø5 $160 \mathrm{~mm}$ long in a quartz test tube of $\varnothing 10 \mathrm{~mm}$. Alloy melting is made, stirring is carried out by a quartz stick and test taking of the initial test (No. 3) is carried out in a ceramic tank. Radiation of the melt was executed out of the furnace. Generator parameters: amplitude was $6 \mathrm{kV}$, frequency was $1 \mathrm{kHz}$. Time of radiation was $15 \mathrm{~min}$. Initial temperature of radiation was $350^{\circ} \mathrm{C}$, finite $-135^{\circ} \mathrm{C}$. Irradiated test was selected in a ceramic tank after melt agitation (test No. 4).

Sawdust was made from the received castings of tests 3 and 4 by a file. The analysis of a chemical composition of sawdust was carried out on the atomic and adsorption spectrophotometer "Quantum-2A". The atomic and adsorption spectrophotometer "Quantum-2A" was certified in the state system. The relative error of the analysis makes $\pm 2 \%$, with confidential probability 0.95. Elements Bi, Cd, Sn, Sb, Cu, Zn, Fe are defined. The $\mathrm{Pb}$ element is defined as "remaining to $100 \%$ ". Analysis results are presented in Table 1.

It is visible that good data fits on the initial test with passport data and good coincidence of balance of transmutation of elements takes place. Also coincidence of balance of elements conversion - the sums of minuses $(-7.4)$ and pluses $(+7.4)-$ is observed.

Experience 2. Radiation of an alloy of $\mathrm{Pb}, \mathrm{Bi}$. The alloy is prepared independently. Lead is granulated, composition in \% masses: $\mathrm{Pb}-99.88, \mathrm{Sb}-0.1$, other $\mathrm{Bi}, \mathrm{Fe}, \mathrm{Cu}, \mathrm{Sn}$, $\mathrm{Ag}$, As less than 0.06); Bismuth is granulated (composition: $\mathrm{Bi}-97.9, \mathrm{~Pb}-1.8, \mathrm{Ag}-0.08$, other $\mathrm{Cu}$, Fe less than 0.001).

The hinge plate from Lead of $0.55 \mathrm{~kg}$ and Bismuth of $0.45 \mathrm{~kg}$ was used for preparation of the melt. The crucible is graphite $\varnothing 55$, height is $95 \mathrm{~mm}$. Lead was heating to $400^{\circ} \mathrm{C}$, then Bismuth was added, stirring was made, a test taking of the initial test (No. 21) was carried out. Radiation of a melt was made out of the furnace. The radiator is the copper

Table 1

Composition of Elements, \% masses

\begin{tabular}{|c|c|c|c|c|}
\hline Element & $\mathrm{Pb}$ & $\mathrm{Bi}$ & $\mathrm{Sn}$ & $\mathrm{Sb}$ \\
\hline Initial, No.3 & 32.3 & 50.0 & 17.5 & 0.2 \\
\hline Irradiated, No. 4 & 39.66 & 43.1 & 17.0 & 0.24 \\
\hline Change & +7.36 & -6.9 & -0.5 & +0.04 \\
\hline
\end{tabular}


rod Ø5, length is $120 \mathrm{~mm}$ in a quartz test tube of $\varnothing 10 \mathrm{~mm}$. Generator parameters: $6 \mathrm{kV}, 1 \mathrm{kHz}$. Time of radiation is $15 \mathrm{~min}$. Initial temperature is $400^{\circ} \mathrm{C}$, finite $-250^{\circ} \mathrm{C}$. The irradiated test (No. 22) was molded after melt agitation. The analysis of tests 21 and 22 in the form of sawdust was carried out on the atomic and adsorption spectrophotometer "Quantum-2A". Results are presented in

\section{Table 2.}

It is visible that the composition of elements in the initial sample is very close to the value determined by the weight composition of $55 \% \mathrm{~Pb}$ and $45 \%$ Bi with the accounting of the additional composition of $1.8 \%$ of Lead in Bismuth. Transformation of $8 \%$ of Bismuth into Lead is watched after radiation. The rule of balance is observed.

Measurement of radioactivity of Lead and Bismuth in the form of sawdust in mass of $1 \mathrm{~g}$ was carried out on low-background installation of UMF-2000. Results of measurements are the next: exceeding of a $\alpha$-radiation background for Lead - by 15 times, for Bismuth - by 7 times. Results of the measurements of activity for initial and irradiated tests are the next: exceeding of a $\alpha$-radiation background for the initial test No. 21 by 6.25 times, for the irradiated test No. 22 - by 14.7 times. There was the significant increase in the $\beta$-radiation level of the irradiated sample after radiation. Measurements of radioactivity of these samples in the year gave background exceeding in the initial test by 5.6 times, in

Table 2

Composition of Elements, \% masses

\begin{tabular}{|c|c|c|c|c|}
\hline Element & $\mathrm{Pb}$ & $\mathrm{Bi}$ & $\mathrm{Sn}$ & $\mathrm{Sb}$ \\
\hline Initial, No.21 & 57 & 43.0 & 0.005 & 0.014 \\
\hline Irradiated, No. 22 & 65 & 35.0 & 0.006 & 0.014 \\
\hline Change & +8.0 & -8.0 & +0.001 & 0 \\
\hline
\end{tabular}

irradiated - by 3.6 times. Level change of $\beta$-radiation is in error limits.

Experience 3. Radiation of Roze alloy $(\mathrm{Pb}, \mathrm{Bi}, \mathrm{Sn})$. The alloy was bought from the manufacturer. Experimental conditions: the mass of an alloy is $0.5 \mathrm{~kg}$, the alundovy crucible with $\varnothing 55$ internal dimensions, depth is $70 \mathrm{~mm}$ in the screen from a copper foil. Radiator is the copper $\operatorname{rod} \varnothing 5,160 \mathrm{~mm}$ long in a quartz test tube of $\varnothing 10$ of $\mathrm{mm}$. Heating of an alloy is made to $400^{\circ} \mathrm{C}$, stirring and a test taking of the initial test (No. 23) are carried out. Generator parameters are $6 \mathrm{kV}, 1 \mathrm{kHz}$, time of radiation is $15 \mathrm{~min}$. Initial temperature is $400^{\circ} \mathrm{C}$, finite $-215^{\circ} \mathrm{C}$. Irradiated test (No. 24) was selected after stirring.

The analysis of tests 23 and 24 in the form of sawdust was carried out on the atomic and adsorption spectrophotometer "Quantum$2 \mathrm{~A}$ ". Results are presented in Table 3.

It is visible that a large amount of Bismuth passed into Lead after radiation. Transition of small part of Tin to Lead is also watched. The rule of balance is observed: $-12.9 \rightarrow+12.9$.

Results of radioactivity measurements of initial and irradiated tests are the next: exceeding of a $\alpha$-radiation background for the initial test - by 115 times, for irradiated test - by 82 times. There was the considerable reduction of the $\alpha$-radiation level of the irradiated sample after radiation. Measurements of radioactivity of these samples in the year gave background exceeding in the initial test by 35.6 times, in

Table 3

Composition of Elements, \% masses

\begin{tabular}{|c|c|c|c|c|}
\hline Element & $\mathrm{Pb}$ & $\mathrm{Bi}$ & $\mathrm{Sn}$ & $\mathrm{Sb}$ \\
\hline Initial, No.23 & 15.4 & 67.0 & 17.4 & 0.2 \\
\hline Irradiated, No. 24 & 28.26 & 55.1 & 16.4 & 0.24 \\
\hline Change & +12.86 & -11.9 & -1.0 & +0.04 \\
\hline
\end{tabular}


the irradiated by 29.6 times. Level change of $\beta$-radiation is in error limits.

Experience 4. Radiation of an alloy of $\mathrm{Pb}$ and $\mathrm{Bi}$. The alloy is prepared independently. The chemical composition of Lead and Bismuth is given in Experience 3. The hinge plate from Lead of $0.17 \mathrm{~kg}(39 \%)$ and Bismuth of $0.27 \mathrm{~kg}(61 \%)$ was used for melting. The crucible is graphite, $\varnothing 45$, height is $95 \mathrm{~mm}$.

Heating of Lead was carried out to $400^{\circ} \mathrm{C}$, then bismuth was added, an exposure was carried out at a temperature $300^{\circ} \mathrm{C}$, stirring, a test taking of the initial test (No. 31). Radiation mode: the radiator is the graphite rod $\varnothing 6$ of $\mathrm{mm}$ without protective tube, depth of dipping is $85 \mathrm{~mm}$. Generator: amplitude is $10 \mathrm{kV}$, keyboard speed of $1 \mathrm{kHz}$. Time of processing is $10 \mathrm{~min}$. Initial temperature is $260^{\circ} \mathrm{C}$, finite $-210^{\circ} \mathrm{C}$. Irradiated test (No. 32) was selected after agitation.

Researches of a chemical composition were conducted on the raster electronic microscope of JEOL JSM-6460LV firm (Japan) with system of microanalysis JXFORD INCA EWC453 (Great Britain). Measurements were made on fresh cross cutoffs of samples. Three sites of $2 \times 3 \mathrm{~mm}$ in size were researched in case of increase equal 30 .

Distinctions on a chemical composition between the initial and irradiated samples by the results of mean values of three measurements are presented in Table 4.

It is visible that there is a considerable change of chemical composition that exceeds the measurement error by 11 times.

Table 4

Mean values of a chemical composition, \% masses

\begin{tabular}{|c|c|c|}
\hline Element & $\mathrm{Pb}$ & $\mathrm{Bi}$ \\
\hline Initial & 30.34 & 69.66 \\
\hline Irradiated & 41.96 & 58.04 \\
\hline Change & +11.62 & -11.62 \\
\hline Error & 1.02 & 1.05 \\
\hline
\end{tabular}

Results of radioactivity measurements are the next: exceeding of $\alpha$-radiation background for Lead - by 2.9 times, for Bismuth - background level. Results of activity measurements of initial and the irradiated tests are: exceeding of $\alpha$-radiation background for the initial test is absent, for irradiated - by 3.6 times. There was an insignificant increase in the $\alpha$-radiation level of the irradiated sample after radiation.

\section{ANALYSIS OF RESULTS}

All our experiments were made using one technique. Melt agitation after preparation was carried out by a quartz stick and then a test "initial" was selected in a ceramic tank. It is known [8] that Lead in case of a melting temperature $327^{\circ} \mathrm{C}$ has density of $10678 \mathrm{~kg} / \mathrm{m}^{3}$, and in a solid status $11350 \mathrm{~kg} / \mathrm{m}^{3}$. Bismuth has density 10050 $\mathrm{kg} / \mathrm{m}^{3}$ in a liquid status in case of a melting temperature $271^{\circ} \mathrm{C}$, and in solid - 9747 $\mathrm{kg} / \mathrm{m}^{3}$, respectively. Therefore, density of Lead will decrease and density of Bismuth will increase in case of extension a melt temperature above a melting temperature. It is possible that these densities will be close at melt temperatures of $350^{\circ} \mathrm{C}-400^{\circ} \mathrm{C}$ under which process of radiation begins and test "initial" is molded. The maximum error can be counted at the expense of a density difference for Lead density of 10.678 and 10.050 for Bismuth. If melt is not absolutely mixed, the density difference will make 628 $\mathrm{kg} / \mathrm{m}^{3}$, this will make $5.9 \%$ in relation to Lead. Receiving of the initial test with the raised content of Bismuth is possible in case of insufficient agitation at the expense of density difference.

The place where test is molded is one more factor influencing on the quality of test. In our experiences tests were selected to 
the ceramic tank of $10 \times 10 \times 70 \mathrm{~mm}$ in size. There is a melt crystallization in it.

The status chart of $\mathrm{Bi}-\mathrm{Pb}$ alloy is used for the characteristic of crystallization process [9]. Crystallization of Lead-Bismuth alloys happens in the range of temperatures. Therefore, a composition of the crystals which are forming at the beginning of solidification can significantly differ from composition of last straws of a crystallizing melt. The temperature interval of alloy crystallization is wider, the segregation develops more strongly. The single alloy of Lead-Bismuth system crystallizing in case of continuous temperature $\left(125^{\circ} \mathrm{C}\right)$ is the alloy of the eutectic composition containing $56 \%$ (at.) Bi.

The following operation was carried out for the analysis of a chemical composition of samples "initial No. 31" and "irradiated No. 32". Research of a transverse section of samples 31 and 32 in the direction from a sample bottom to its top in 8 areas was carried out by means of micro ray spectral analysis by a Carl Zeiss firm microscope. The area of measurement surface makes $\approx 0.5 \times 0.5 \mathrm{~mm}$. An exception method of results connected with casting boundaries - upper and lower is used when processing of analysis results of metal castings. Mean values on 6 layers are given in Table 5 .

These values are less than the data specified in Table 4.

Table 5

Chemical composition of samples, \% masses

\begin{tabular}{|c|c|c|}
\hline Element & $\mathrm{Pb}$ & $\mathrm{Bi}$ \\
\hline Initial, No. 31 & 49.6 & 50.4 \\
\hline Irradiated, No.32 & 59.6 & 40.1 \\
\hline Change & +10.0 & -10.3 \\
\hline
\end{tabular}

All abovementioned results belonged to analyses of solid samples. The raster electron microscope allows to analyze the samples in the form of powders and sawdust. Sawdust from samples 31 and 32 in the cross direction was saw by a smallsized file for results comparison. This sawdust on a neutral glue basis was pasted on the end face of the rod $\varnothing 4 \mathrm{~mm}$ which was set in the analysis camera. The area of an analyzable surface made $\approx 10 \mathrm{~mm}^{2}$. Data of the carried-out analysis are given in Table 6.

These data are very close to data given in Table 4.

An analysis of samples 31 and 32 was carried out also on the atomic and emissive spectrometer "Spektroflame Modula S" with the inductive and connected plasma. Hinge plate of an alloy of $0.22 \mathrm{~g}$ before the analysis dissolved in imperial vodka $(\mathrm{HCl}$ : $\left.\mathrm{HNO}_{3}=3: 1\right)$ in case of heating up. The hinge plate was received by shaving drilling by a drill with a diameter of $3 \mathrm{~mm}$ in the vertical direction of a sample. Solution was transferred to measured flasks after full dilution of a hinge plate and then measured volumes used for the analysis were taken. Concentration measurements were carried out with the use of standard components method. It was carried out in two measurements. Analysis data are presented in Table 7.

All data of the content measurement of Lead and Bismuth in samples 31 and 32

Table 6 Chemical composition of samples 31 and 32 (sawdust), \% masses

\begin{tabular}{|c|c|c|}
\hline Element & $\mathrm{Pb}$ & $\mathrm{Bi}$ \\
\hline Initial, No. 31 & 29.1 & 70.9 \\
\hline Irradiated, No.32 & 40.97 & 59.3 \\
\hline Change & +11.87 & -11.6 \\
\hline
\end{tabular}


Table 7

Average composition of elements, $\%$ masses

\begin{tabular}{|c|c|c|}
\hline Element & $\mathrm{Pb}$ & $\mathrm{Bi}$ \\
\hline Initial, No. 31 & 34.5 & 65.65 \\
\hline Irradiated, No. 32 & 44.6 & 55.15 \\
\hline Change & +10.1 & -10.5 \\
\hline
\end{tabular}

under different conditions of measurement are given together below for convenience of comparing (Table 8).

Data in Table 8 unambiguously specify the reduction of the Bismuth content and increase of the Lead content during radiation.

\section{THEORETICAL SUBSTANTIATIONS}

The theory of electron capture is one of hypotheses for theoretical reasons for transmutation of $\mathrm{Bi} \rightarrow \mathrm{Pb}$ under the influence of NEMI [3]. According to this theory change of atomic mass doesn't happen, and one of bismuth protons becomes a neutron. We will use the table from [10] for the analysis of isotope composition of long-living isotopes of lead and bismuth.

The new result about an isotope ${ }^{209} \mathrm{Bi}$ is received [11]. It is revealed its $\alpha$-radiation with energy $3.13 \mathrm{keV}$ and the half-life period of $1.9 \times 10^{19}$ years is defined. The isotope ${ }^{204} \mathrm{~Pb}$ is specified as stable in literature. However, it is specified as radioactive with a half-life period of $1.4 \times 10^{17}$ years [10]. Existence $\alpha$-activity of the initial and irradiated samples in experiences 3, 4, 5 and its change within the time in experiences 3 and 4 specify existence and change of the isotopic composition after NEMI radiation.

Table 8 Changes of the composition of $\mathrm{Pb}$ and $\mathrm{Bi}$ of samples 31 and 32, \% masses

\begin{tabular}{|l|c|c|c|}
\hline \multicolumn{1}{|c|}{ Element } & $\mathrm{Pb}$ & $\mathrm{Bi}$ & Analyzer \\
\hline Metal, 3 platforms & +11.97 & -11.97 & JEOL \\
\hline Sawdust, $10 \mathrm{~mm}^{2}$ & +11.87 & -11.6 & JEOL \\
\hline Metal, 6 platforms & +10.0 & -10.3 & Carl Zeiss \\
\hline Shaving, 2 measurements & +10.1 & -10.5 & Spektroflame Modula S \\
\hline
\end{tabular}

From table data [10] it's visible that if there are isotopes ${ }^{210 \mathrm{~m}} \mathrm{Bi},{ }^{208} \mathrm{Bi}$ and ${ }^{207} \mathrm{Bi}$ in a melt before radiation, they will give a long-living isotope of Lead ${ }^{210} \mathrm{~Pb}$ or stable isotopes ${ }^{208} \mathrm{~Pb}$ and ${ }^{207} \mathrm{~Pb}$ after NEMI radiation. The isotope ${ }^{209} \mathrm{~Pb}$ has small time of half-life. There would be the considerable change of analysis results during time in case of its existence. This effect wasn't watched. Unfortunately, we had no instruments for measurement of the isotopic composition of Bismuth and Lead. Therefore, it is necessary to consider the offered transitions ${ }^{210 \mathrm{~m}} \mathrm{Bi} \rightarrow{ }^{210} \mathrm{~Pb},{ }^{208} \mathrm{Bi} \rightarrow{ }^{208} \mathrm{~Pb}$ and ${ }^{207} \mathrm{Bi} \rightarrow{ }^{207} \mathrm{~Pb}$ as a scientific hypothesis.

\section{CONCLUSION}

The provided data of experimental researches indicate a possibility of transformation of tens of grams of bismuth into lead under the influence of pulse fields with big degree of reliability. Data are easily checked. It is possible to get generators of impulses in "Fid-Tekhnologiya" firm (St. Petersburg). It is necessary to pay special attention to bismuth choosing initial materials. It is possible to receive coefficient of transformation of bismuth into lead about 3\% if the choice of bismuth is unsuccessful. All other conditions of experiences are described above in detail.

From the analysis of experiences on water solutions it is possible to specify one more couple of elements - copper and nickel in which the similar phenomena can occur.

\section{REFERENCES}

1. Balakirev VF, Krymsky VV, Kulakov BA, Ri Khosen. Elektroimpul'snye nanotekhnologii [Electropulse Nanotechnologies]. Ekaterinburg, Ural Office of Russian Academy of Sciences Publ., 2009, 141 p.

2. Shaburova NA. Obrabotka metallov $i$ splavov nanosekudnymi elektromagnitnymi impul'sami [Processing of Metals and Alloys by 
Nanosecond Electromagnetic Impulses]. Chelyabisk, TsNTI Publ., 2011, 94 p.

3. Balakirev VF, Krymsky VV, Shaburova NA. Nanoimpul'snye tekhnologii [Nanopulse Technologies]. Chelyabisk, TsNTI Publ., 2012, $124 \mathrm{p}$.

4. Krymski VV, Shaburova NA, Filimonov IE. Pulse electromagnetic effect on metal melts. J. of Chemistry and Chemical Engineering, 2012, 6(11):967.

5. Urutskoev LI, Liksonov VI, Tsinoev VG. Prikladnaya firika, 2000, 4:83-100 (in Russ.).

6. Krymsky VV, Balakirev VF. Doklady RAN [Reports of Russian Academy of Sciences], 2002, 385(6):786-787 (in Russ.).

7. Balakirev VF, Krymsky VV, Bolotov BV, Vasil'eva NV, Vachaev AV, Ivanov NI, Kazbanov VI, Pavlova GA, Solin MI, Trofimov VI, Urutskoev LI. $V$ zaimoprevrasheniya kbimicheskikh elementov [Interconversions of Chemical Elements]. Ekaterinburg, Ural Office of Russian Academy of Sciences Publ., 2003, 93 p.

8. Emsley J. The Elements. Oxford, Clarendon press, 1991, $256 \mathrm{p}$.

9. Budberg PB, Alisova SP. Diagrammy sostoyaniya dvoynykh $i$ mnogokomponentnykh system na osnove zheleza [Charts of a Condition of Double and Multicomponent Systems on the Basis of Iron]. Moscow, Metallurgiya Publ., 1986, 525 p.

10. Shirokov YuM, Yudin NP. Yadernaya fizika [Nuclear Physics]. Moscow, Nauka Publ., 1980, 727 p.

11. Varcillac P, Coron N, Dambier G, Leblanc J, Moalik JP. Experimental detection of alpha-particles from the radioactive decay of natural bismuth. Nature, 2003, 422(6934):876-878. 